Article

\title{
Spatial Upscaling of Soil Respiration under a Complex Canopy Structure in an Old-Growth Deciduous Forest, Central Japan
}

\author{
Vilanee Suchewaboripont ${ }^{1}$, Masaki Ando ${ }^{2}$, Shinpei Yoshitake ${ }^{3}$, Yasuo Iimura ${ }^{4}$, \\ Mitsuru Hirota ${ }^{5}$ and Toshiyuki Ohtsuka ${ }^{1,3, *}$ \\ 1 United Graduate School of Agricultural Science, Gifu University, 1-1 Yanagido, Gifu 501-1193, Japan; \\ vilanee.s@hotmail.com \\ 2 Laboratory of Forest Wildlife Management, Faculty of Applied Biology Sciences, Gifu University, \\ 1-1 Yanagido, Gifu 501-1193, Japan; m_ando@gifu-u.ac.jp \\ 3 River Basin Research Center, Gifu University, 1-1 Yanagido, Gifu 501-1193, Japan; \\ syoshi@green.gifu-u.ac.jp \\ 4 School of Environmental Science, The University of Shiga Prefecture, Hikone, Shiga 522-8533, Japan; \\ iimura.y@ses.usp.ac.jp \\ 5 Faculty of Life and Environmental Sciences, University of Tsukuba, Tsukuba, 305-8577, Japan; \\ hirota@biol.tsukuba.ac.jp \\ * Correspondence: toshi@green.gifu-u.ac.jp; Tel.: +81-58-293-2065
}

Academic Editors: Robert Jandl and Mirco Rodeghiero

Received: 6 December 2016; Accepted: 24 January 2017; Published: 30 January 2017

\begin{abstract}
The structural complexity, especially canopy and gap structure, of old-growth forests affects the spatial variation of soil respiration $\left(R_{s}\right)$. Without considering this variation, the upscaling of $R_{S}$ from field measurements to the forest site will be biased. The present study examined responses of $R_{S}$ to soil temperature $\left(T_{S}\right)$ and water content $(W)$ in canopy and gap areas, developed the best fit model of $R_{S}$ and used the unique spatial patterns of $R_{S}$ and crown closure to upscale chamber measurements to the site scale in an old-growth beech-oak forest. $R_{S}$ increased with an increase in $T_{S}$ in both gap and canopy areas, but the effect of $W$ on $R_{s}$ was different between the two areas. The generalized linear model (GLM) analysis identified that an empirical model of $R_{S}$ with the coupling of $T_{S}$ and $W$ was better than an exponential model of $R_{s}$ with only $T_{s}$. Moreover, because of different responses of $R_{S}$ to $W$ between canopy and gap areas, it was necessary to estimate $R_{S}$ in these areas separately. Consequently, combining the spatial patterns of $R_{s}$ and the crown closure could allow upscaling of $R_{S}$ from chamber-based measurements to the whole site in the present study.
\end{abstract}

Keywords: soil respiration; spatial variation; gap/canopy structure; upscaling; old-growth forest

\section{Introduction}

Studies of soil respiration $\left(R_{s}\right)$ have been conducted in many temperate forests and show the temporal variation at both diurnal [1] and seasonal [2-4] time scales. The diurnal variation in $R_{S}$ is explained by plant physiology, especially photosynthesis [1], and soil temperature $\left(T_{s}\right)$ [5]. The seasonal variation in $R_{S}$ is primarily controlled by $T_{S}$ when the soil water content $(W)$ is not limited, and the response of $R_{S}$ to $T_{S}$ is usually explained by an exponential $\left(\mathrm{Q}_{10}\right)$ relationship [6-8]. Under drought conditions, $W$ and $T_{S}$ are considered to be coupled factors in relation to their effect on $R_{S}[9,10]$. Continuous measurement of the effects of $T_{S}$ and $W$ on $R_{S}$ is required for the scaling up of $R_{S}$ from chamber-based measurements to a forest ecosystem. Some studies on the effects of $T_{S}$ and $W$ on $R_{S}$ have been conducted using an automatic opening and closing chamber (AOCC) system. Although this approach is based on the closed dynamic method, the AOCC system allows continuous 
measurement of $R_{S}$ on both short- and long-term scales and provides the detail needed to develop our understanding of the relationships between $R_{S}$ and environmental variables [3,11-14]. Moreover, this system minimizes disturbance of the soil surface during $R_{S}$ measurements.

Many old-growth forests show canopy structural complexity, particularly canopies and gaps [15-20]. The complex structure of canopies related to forest age facilitates a greater harvesting of light than a simple structure, and thus it increases net primary production [21,22]. This structural complexity also reflects the spatial variation in $R_{s}$, which is greater in canopy areas than in gap areas $[23,24]$. Despite the fact that these $R_{s}$ patterns impact the upscaling of $R_{s}$ to the forest ecosystem level, only a few publications focusing on the upscaling method based on spatial variation in $R_{S}$ are available. For example, Tang and Baldocchi [25] used crown closure and different rates of $R_{s}$ between areas under trees and open areas to spatially upscale $R_{S}$ to a whole site in an oak-grass savanna ecosystem in California.

In a recent study of $R_{S}$ in an old-growth beech-oak forest in central Japan, the effect of the complexity of the vertical structure, especially the canopy/gap structure, on the spatial variation of $R_{S}$ was investigated [24]. The $R_{S}$ was greater in canopy areas than in gap areas during the growing season, and there was no significant difference in $T_{S}$ or $W$ between canopy and gap areas. However, diurnal and seasonal changes in $R_{S}$ and these environmental factors have not been studied, and the responses of $R_{s}$ to changes in $T_{s}$ and $W$ in canopy and gap areas are unclear. Consequently, the present study aims to (1) quantify the temporal variation of $R_{S}$ in canopy and gap areas; (2) characterize the response of $R_{S}$ to $T_{S}$ and $W$ in canopy and gap areas; (3) develop models for $R_{S}$ determined as a function of $T_{S}$ and $W$; and (4) upscale chamber measurements of $R_{s}$ to the site scale based on the spatial patterns of $R_{s}$ between canopy and gap areas and crown closure. We used the AOCC system to measure $R_{s}$ continuously in order to understand the relationships between $R_{S}$ and environmental variables and to develop suitable models of $R_{S}$ for estimation of annual $R_{S}$.

\section{Materials and Methods}

\subsection{Study Site}

The study site $\left(36^{\circ} 9^{\prime} \mathrm{N}, 136^{\circ} 49^{\prime} \mathrm{E}, 1330 \mathrm{~m}\right.$ above sea level) is located in primary deciduous broad-leaved forests around the Ohshirakawa river basin (840-1600 $\mathrm{m}$ above sea level) on the mid slope of Mt. Hakusan. The forests became established since the last eruption of Mt. Hakusan in 1659 [26] and are protected by the Hakusan National Park under the management of the Forest Agency of Japan and the Ministry of Environment, Japan. No evidence of human disturbance in this area was found before the 1960s. After the construction of the Ohshirakawa dam (approximately $800 \mathrm{~m}$ from the study site) in the 1960s, this area has been accessed by local people for the collection of mushrooms, bamboo shoots and chestnuts [20].

A permanent 1-ha $(100 \mathrm{~m} \times 100 \mathrm{~m})$ plot of primary forest was reconstructed to examine carbon cycling of the forest ecosystem during July 2011 after a first construction of the plot in 1993 [27]. This plot is on an east-facing gentle slope with an average slope of 3 degrees. In the study plot, the canopy layer is dominated by Fagus crenata (beech, $47.6 \%$ of basal area) and Quercus mongolica var. crispula (oak, 37.4\% of basal area) trees with diameters at breast height (DBH) of $\geq 25 \mathrm{~cm}$ and heights of approximately 25-30 m. The sub-tree layer comprises beech, Acer tenuifolium, and Vibrunum furcatum, with high stem densities and heights of 10-15 m. Evergreen dwarf bamboo (Sasa kurilensis) of 1.5-2.0 m in height sparsely covers the forest floor. The DBHs of all trees were measured in 2014, and tree biomasses were estimated following Suchewaboripont et al. [20]. The aboveground biomass (except for leaves) of canopy trees was large, i.e., $475.9 \mathrm{Mg} \mathrm{ha}^{-1}$. Most of this biomass consisted of canopy trees of beech (45.9\%) and oak (46.7\%), and the DBH of these trees ranged from 25.75 to $101.28 \mathrm{~cm}$ and 44.31 to $195.04 \mathrm{~cm}$, respectively. The forest age is $>250$ years, and the age of a dead oak tree $(\mathrm{DBH}=74.5 \mathrm{~cm})$ near the study plot was determined as being over 258 years. The soil in the study plot is volcagogenous regosol with thin A $(0-18 \mathrm{~cm})$ and $B(19-24 \mathrm{~cm})$ horizons [20]. 
Air temperature during 2013-2014 in the study plot was monitored using a data logger (HOBO weather station, Onset Computer, Bourne, MA, USA). Air temperature was measured every $30 \mathrm{~min}$, and the data were processed to provide an average every $24 \mathrm{~h}$. The annual mean air-temperature was $5.8^{\circ} \mathrm{C}$, with a maximum daily temperature of $22.7^{\circ} \mathrm{C}$ during August and a minimum daily temperature of $-13.2{ }^{\circ} \mathrm{C}$ during February. The average annual precipitation during 2013-2014 was $3289 \mathrm{~mm}$, measured at Miboro weather station $\left(36^{\circ} 9^{\prime} \mathrm{N}, 136^{\circ} 54^{\prime} \mathrm{E}, 640 \mathrm{~m}\right.$ above sea level). Heavy snowfall from November to April resulted in accumulated snow depths of $>4 \mathrm{~m}$ in 2013.

\subsection{Measurement of the Soil $\mathrm{CO}_{2}$ Efflux}

To define the gap and canopy areas for measurement of $R_{S}$ in the study plot, we followed the definitions used in our previous study [24]. Ground areas under canopy openings ( $\geq 5 \mathrm{~m}^{2}$ in area) caused by canopy tree deaths were defined as gap areas [28], and the areas under canopy trees were defined as canopy areas. In the study plot, it was difficult to choose the most suitable areas for placing an AOCC system, in particular, and measuring $R_{s}$ and environmental factors due to varying density of sub-trees (shown as their basal areas in Figure 1b) and Sasa (Figure 1c). However, we selected three canopy (C1, C2, and C3) and two gap (G1 and G2) areas for measurement of their $R_{s}$ and environmental factors.

(a)



(b)

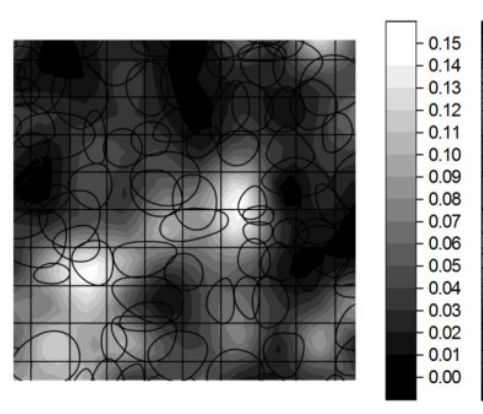

(c)

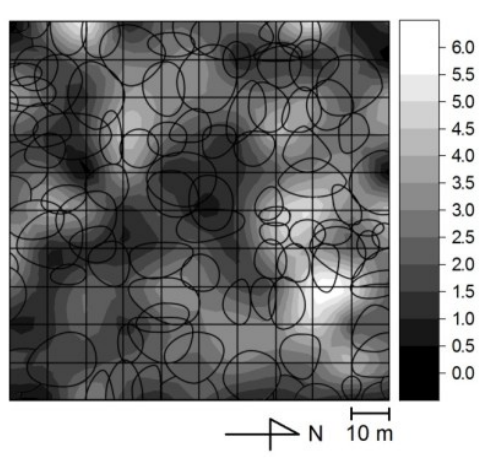

Figure 1. Five locations for measurement of soil respiration $\left(R_{S}\right)$ and environmental factors based on the crown projection diagram (a); the basal area in the sub-tree layer (b); and the density of dwarf bamboo (c) (from Suchewaboripont et al. [24]). Basal areas of sub-trees $(\mathrm{DBH}<25 \mathrm{~cm}$ ) and stem densities of Sasa are presented as $\mathrm{m}^{2}$ and stem numbers $\mathrm{m}^{-2}$, respectively.

Changes in $\mathrm{CO}_{2}$ efflux from soil $\left(R_{S}\right)$ were measured continuously for $24-48 \mathrm{~h}$ once a month by the closed-chamber method with an infrared gas analyzer (IRGA) (GMP343, Vaisala Ltd., Vantaa, Finland). Three chambers $\left(25 \mathrm{~cm}\right.$ internal diameter and $25 \mathrm{~cm}$ height) were installed in each area. $R_{s}$ in all chambers in each area was measured using an AOCC system. The AOCC system had a similar concept to that used by Hirota et al. [29]. Without electricity at the study site, this system was connected to two 12-volt DC car batteries as its electric power for continuous measurement around 2-3 days. The system comprised an automated lid arm subsystem (Figure 2) and a control system for timing the opening and closing of the lid arm. The lid was attached to an IRGA for the measurement of $R_{s}$ in the closed chambers. Rotation of the automated lid arm progressed from chamber 1 to chamber 2 to chamber 3 (Figure 2), with one such cycle taking approximately $16 \mathrm{~min}$. After the closure of chamber 3 , the lid arm returned to chamber 1 and started a new rotation cycle. During chamber closure for $5 \mathrm{~min}, R_{S}$ was measured, and all data were recorded by a data logger (Thermic 2300, Etodenki, Tokyo, Japan) at intervals of $10 \mathrm{~s}$. 


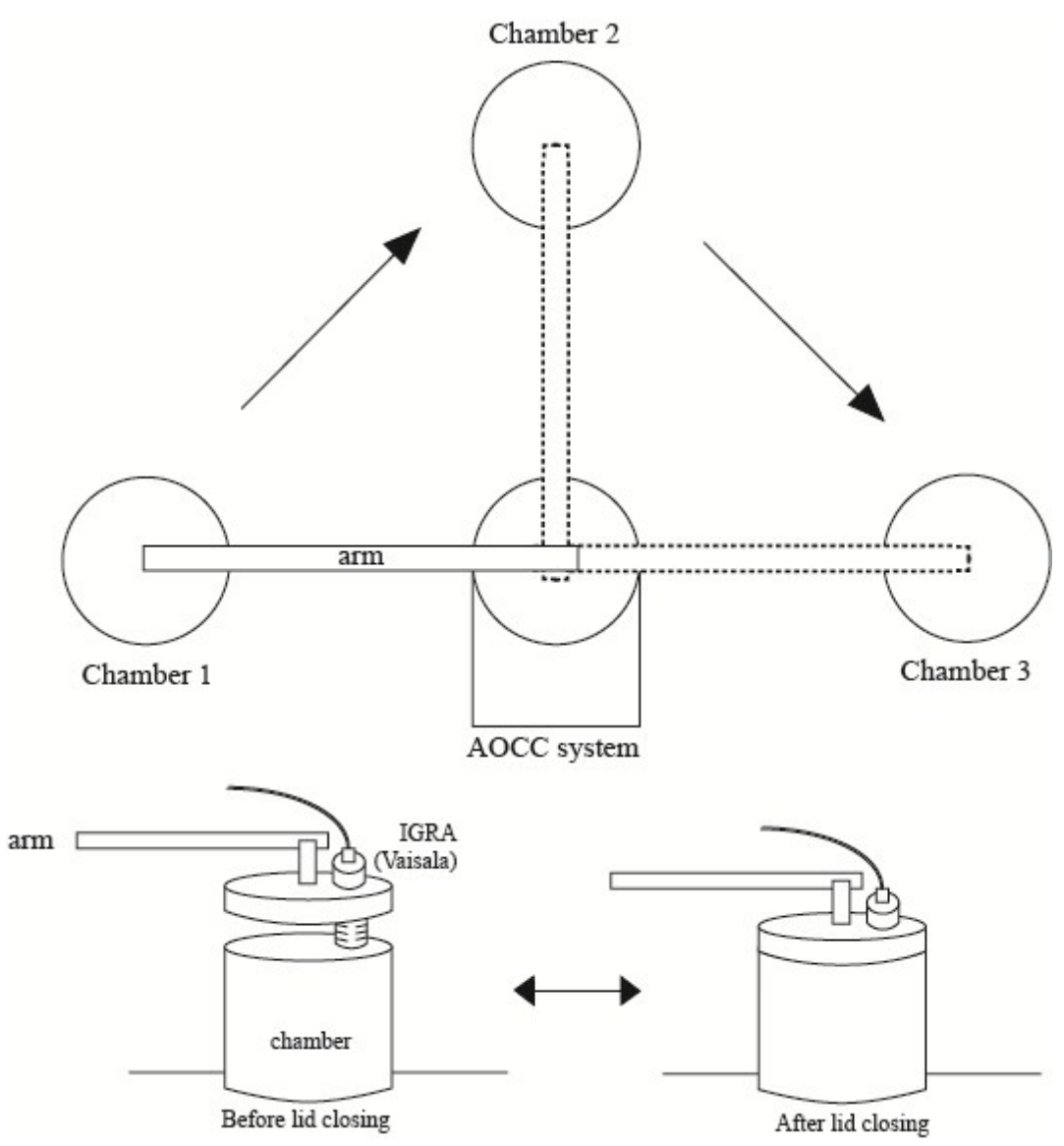

Figure 2. Automatic opening and closing chamber (AOCC) system for measurement of $R_{S}$ in three chambers. The lid connected to the arm of the AOCC system closed the chamber for a 5-min interval. The arm rotated from chamber 1 to chamber 2 to chamber 3 . After measurement completion in chamber 3 , the arm rotated back to chamber 1 for the next cycle. $R_{S}$ in a chamber was continuously measured using an infrared gas analyzer (IRGA) (GMP343, Vaisala Ltd., Vantaa, Finland).

In 2013, we measured $R_{S}$ in C1 and G1 areas during 25-28 June and in all areas from July to October (16-19 July, 19-23 August, 24-28 September, and 22-26 October). In 2014, we measured $R_{S}$ in C1 and G1 areas from June to October (16-18 June, 15-17 July, 2-4 September, 8-10 October, and 29-31 October). In August 2014, $R_{S}$ was not measured because of an extended period of rainy days.

\subsection{Measurement of Soil Temperature and Water Content}

Soil temperature $\left(T_{s}\right)$ in all canopy and gap areas was measured at a depth of $5 \mathrm{~cm}$ in close proximity to the AOCC system using a copper-constantan thermocouple during the same experimental period as the measurement of $R_{S}$. From 23 June 2013 to 30 October 2014, $T_{s}$ was monitored every $10 \mathrm{~min}$ by temperature sensors and data loggers (TidbiT v1 Temp logger, Onset Computer Co., Ltd., Massachusetts, USA). The $T_{S}$ data were processed to provide an average every $1 \mathrm{~h}$.

Soil water content $(W)$ was measured continuously at a depth of $5 \mathrm{~cm}$ near the AOCC system in C1, C3, G1, and G2 from 27 June to 27 October 2013 using a thetaprobe ML2x-L5 (Delta-T Devices, Camblidge, UK) connected to a data logger (THLOG-2, Dynamax Inc., Texas, USA). In C2, W near the AOCC system was measured from 25 September to 27 October 2013 using a SM200 soil moisture sensor (Delta-T Devices, England) connected to a data logger (3635-25 voltage logger, Hioki E.E. Corporation, Nagano, Japan). During the growing season (3 June-29 October) of 2014, W in G1 and $\mathrm{C} 1$ was continuously measured using an SM200 soil moisture sensor. Because of the use of different sensors for measuring $W$, each sensor was calibrated using the field calibration equation reported by 
Abbas et al. [30]. The measurements of $W$ in all areas were taken every $15 \mathrm{~min}$, and the data were processed to provide an average every $1 \mathrm{~h}$.

\subsection{Data Analysis}

$R_{S}$ was calculated on the basis of the linear increase in $\mathrm{CO}_{2}$ concentration in the closed chamber using equation [14]:

$$
R_{\text {s_hourly }}\left(\mathrm{g} \mathrm{C} \mathrm{m}^{-2} \mathrm{~h}^{-1}\right)=\Delta \mathrm{CO}_{2} \times 10^{-6} \times \rho \times V \times A^{-1} \times 60 \times 60 \times 12 / 44,
$$

where $\Delta \mathrm{CO}_{2}$ is the increase in $\mathrm{CO}_{2}$ concentration in the chamber (ppm. $\mathrm{s}^{-1}$; Figure 3), $\rho$ is the density of $\mathrm{CO}_{2}$ in the air, $V$ is the volume of the chamber $\left(\mathrm{m}^{3}\right)$, and $A$ is the soil surface area $\left(\mathrm{m}^{2}\right)$. The average $R_{S}$ in each area was calculated as the mean of all three chambers during 1 cycle of the AOCC system.



Figure 3. Changes in $\mathrm{CO}_{2}$ concentration in chambers during the measurements using the AOCC system. $\triangle \mathrm{CO}_{2}$ was calculated from the intervals, which are evident from the high and low values that intersect the dotted lines.

To examine the response of $R_{s}$ to $T_{s}$ and $W$, these parameters were fitted using an exponential equation [31] as follows

$$
R_{s}=a e^{b T_{s}} W^{c},
$$

where $R_{S}$ is soil respiration $\left(\mathrm{g} \cdot \mathrm{C} \cdot \mathrm{m}^{-2} \cdot \mathrm{h}^{-1}\right), T_{s}$ is soil temperature at a $5 \mathrm{~cm}$ depth $\left({ }^{\circ} \mathrm{C}\right), W$ is soil water content at a $5 \mathrm{~cm}$ depth (\%) and $a, b$ and $c$ are fitted coefficients. To estimate the coefficients $a, b$ and $c$ and fit the model using generalized linear models (GLM) analysis, Equation (2) was transformed as

$$
\log R_{s}=\log a+b T_{\mathrm{s}}+c \log W,
$$

Thus, the full model for GLM analysis with a Gamma distribution and a log link function was expressed as

$$
R_{s} \sim a^{\prime}+b T_{\mathrm{s}}+c \log W,
$$

Moreover, the temperature sensitivity parameter $\left(\mathrm{Q}_{10}\right)$ was calculated as follows:

$$
\mathrm{Q}_{10}=e^{10 b},
$$


Akaike's information criterion (AIC) was used to verify the accuracy of the $R_{S}$ models. The best fitting model with the minimum AIC represented the accuracy of the best-fit $R_{s}$ model. The analysis of models was performed using $R$ version 3.0.3 [32] and library lme4 version 1.1-6 [33].

Annual $R_{S}$ was estimated by summation of hourly $R_{S}$ using $W$ and $T_{S}$ of areas $C 1$ and G1 because both $W$ and $T_{\mathrm{s}}$ in these areas were continuously recorded during the experimental period. However, the continuous measurement of $W$ in the growing season could not be completed in both 2013 and 2014. Thus, annual $R_{s}$ was estimated from 27 September 2013 to 26 September 2014 . The data from 27 September to 27 October 2013 and from 4 June to 26 September 2014 were used to estimate $R_{s}$ for the growing season, and $R_{S}$ during the snow period was summed from 28 October 2013 to 3 June 2014. Because of no effect of $W$ on $R_{S}$ during the snow period, $R_{S}$ during this period was estimated using the exponential relationship with $T_{s}$.

Upscaling $R_{s}$ from the chamber measurements to the site scale was conducted on the basis of the spatial pattern of $R_{S}$ between gap and canopy areas and the area of crown closure at the study site [25]. Model-estimated $R_{S}$ in gap and canopy areas was used to represent $R_{S}$ in canopy and gap areas in the study plot. Then, crown closure was used as a weighting factor to spatially transfer $R_{s}$ over the whole study plot. This simple equation is defined as

$$
F=F_{c} \times c+F_{g} \times(1-c),
$$

where $F$ is $R_{S}$ over the whole study site, $F_{g}$ and $F_{c}$ are the $R_{s}$ values for the gap and canopy areas, respectively, and $c$ is the crown closure measured by the vertically projected crown area divided by the whole study area. The crown closure of the study site was estimated on the basis of the crown projection diagram using Adobe Photoshop (Adobe Systems Incorporated, San Jose, California, USA) [24]. The areas of gap and canopy were estimated to be $25.6 \%$ and $74.4 \%$, respectively, of the entire area.

\section{Results}

\subsection{Temporal Changes in Soil Temperature and Soil Water Content}

Clear temporal changes of $T_{S}$ in gap and canopy areas were observed in the study plot (Figure 4). $T_{S}$ rapidly increased after snow melt in May, and it trended to be higher in canopy areas than in gap areas. $T_{S}$ in all areas peaked in August. After September, $T_{S}$ in all areas dropped to nearly $0{ }^{\circ} \mathrm{C}$ during snowfall. There were no clear differences in $T_{S}$ between canopy and gap areas along the time course, although $T_{S}$ in canopy areas trended to be lower than in gap areas under snow cover.

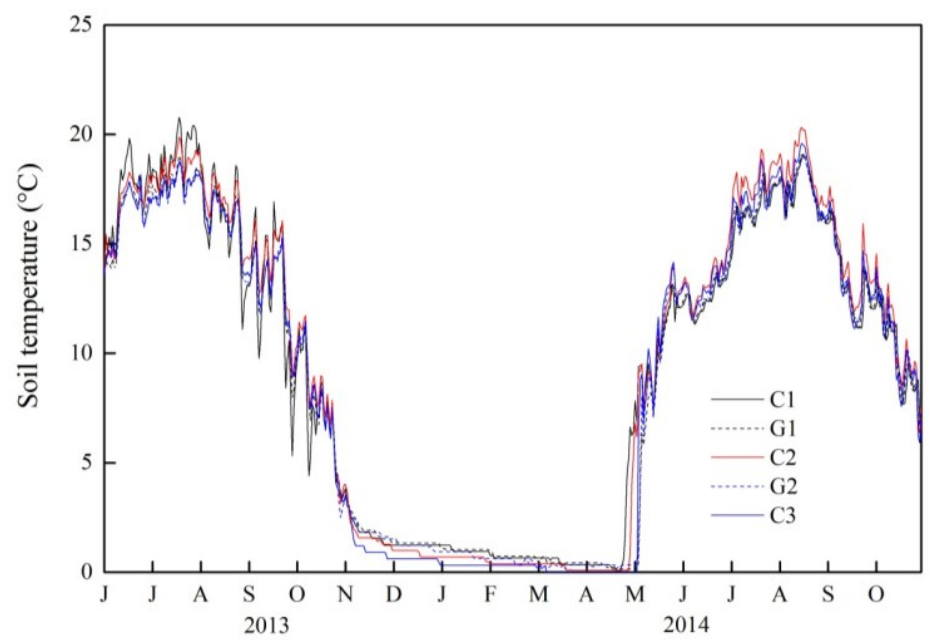

Figure 4. Temporal changes in soil temperature $\left(T_{s}\right)$ at a depth of $5 \mathrm{~cm}$ in gap and canopy areas. 
In 2013 (Figure 5a) and 2014 (Figure 5b), W did not show clear temporal changes in either the canopy or gap areas. In 2013, W was low in August, late September, and early October, although precipitation was recorded during these periods. In 2014, $W$ was low in late June, late July, and September, but it was high in August because of a long period of rainy days.
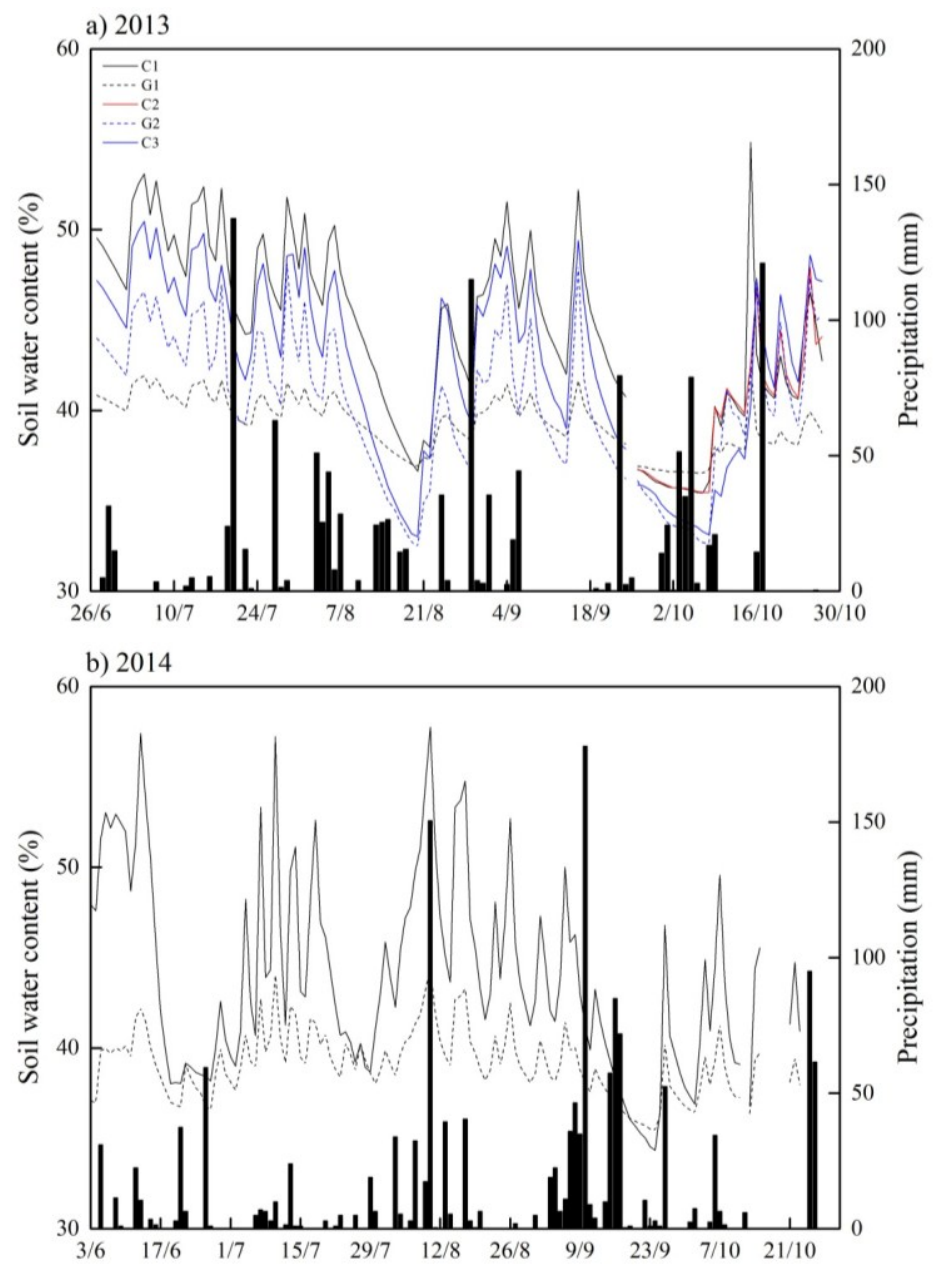

Figure 5. Temporal changes in soil water content $(W)$ at a depth of $5 \mathrm{~cm}$ during the growing seasons of 2013 (a) and 2014 (b). Precipitation data were provided by Miboro weather station.

\subsection{Diurnal Changes in Soil Temperature, Soil Water Content, and Soil Respiration}

Diurnal $R_{s}, T_{s}$, and $W$ at $C 1$ and G1 were continuously monitored on measurement days during the 2014 growing season (Figure 6). $T_{s}$ in both canopy and gap areas showed a diurnal pattern that was highest in the afternoon (around 1-3 p.m.) and lowest in the early morning (around 6 a.m.). $R_{s}$ also showed a similar diurnal pattern to $T_{S}$, i.e., high in the afternoon and low in the early morning. However, except in late October, $W$ did not show a clear diurnal pattern, although this was not investigated thoroughly in October. Diurnal $W$ was likely similar between canopy and gap areas in the middle of June and July because of typical soil drying during these months. In October, diurnal $W$ was higher in canopy areas than in gap areas because of the effect of rain a few days before the measurement day. 
Canopy

a) 19 June



c) 15-16 July

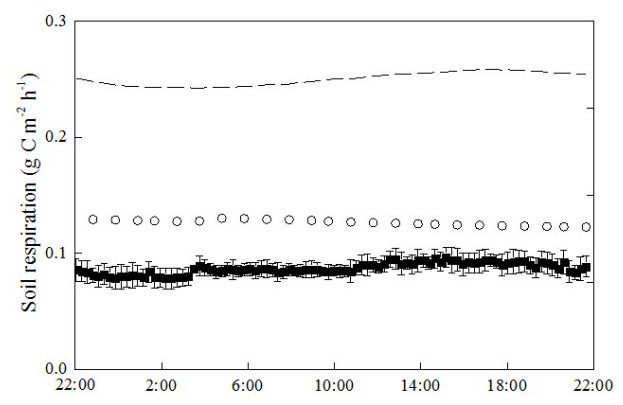

e) 8-9 October

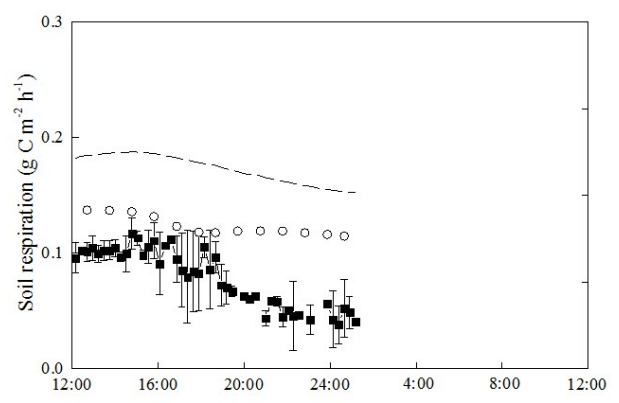

g) 29-30 October

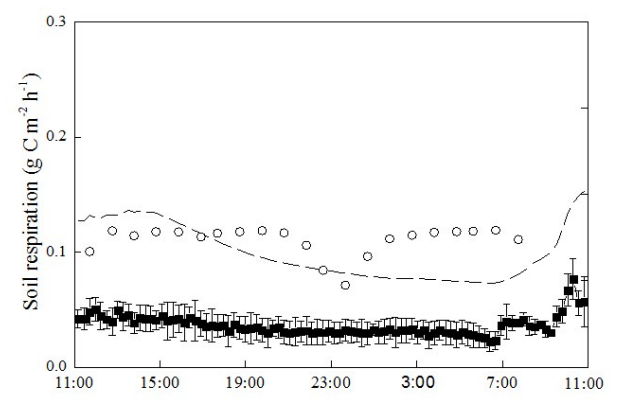

Gap

b) 19 June

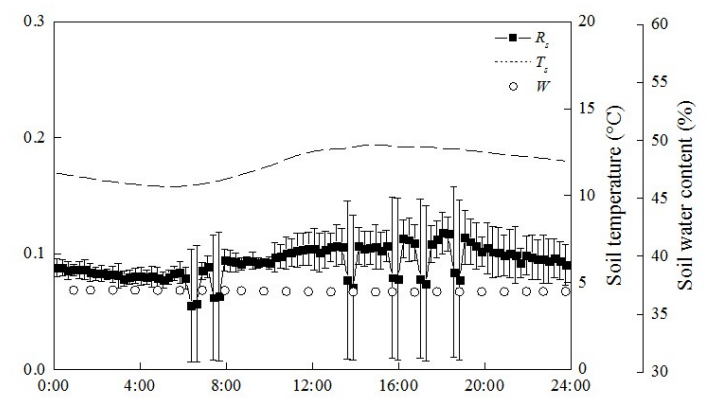

d) 15-16 July

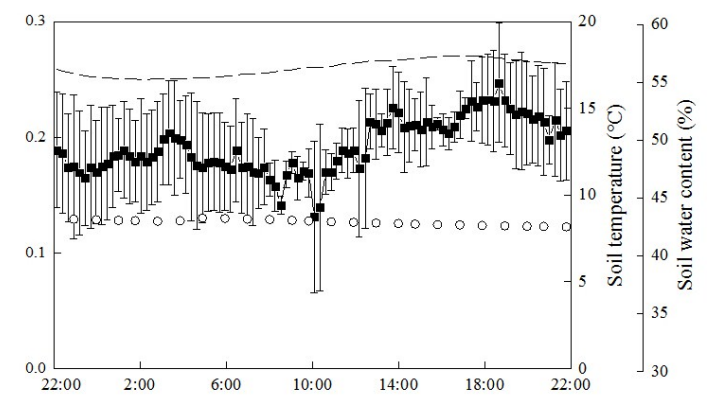

f) 8-9 October

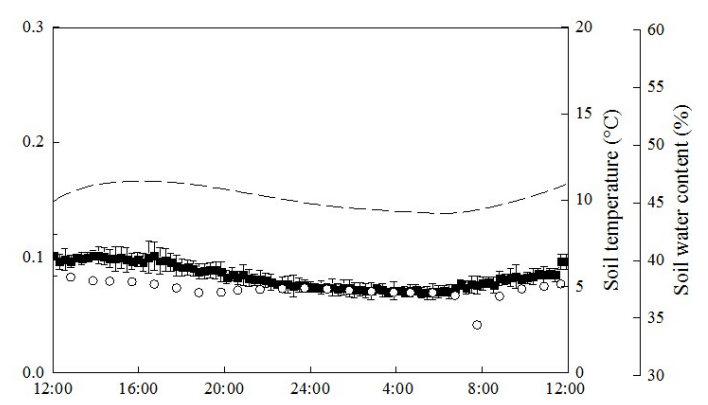

h) 29-30 October

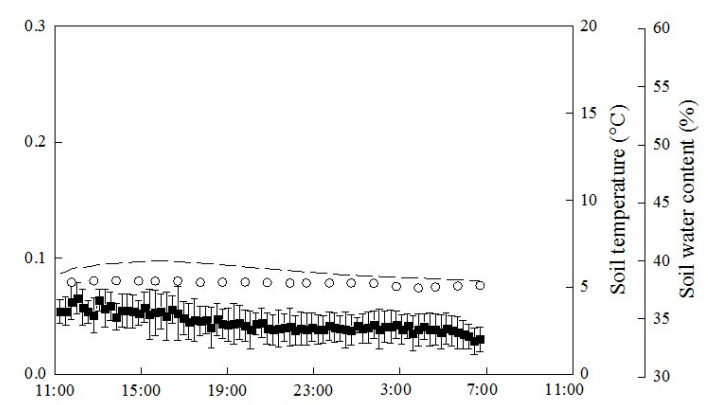

Figure 6. Diurnal patterns of soil respiration $\left(R_{S}\right)$ measured using the AOCC system, soil temperature $\left(T_{s}\right)$, and soil water content $(W)$ for canopy and gap areas during 19 June $(\mathbf{a}, \mathbf{b}), 15-16$ July $(\mathbf{c}, \mathbf{d}), 8-9$ October $(\mathbf{e}, \mathbf{f})$ and 29-30 October $(\mathbf{g}, \mathbf{h})$ 2014. Diurnal $R_{s}$ at C1 in September and early October could not be measured because of problems with automatic chamber closure. Error bar represents the standard error of the mean. 


\subsection{Effect of Soil Temperature and Soil Water Content on Soil Respiration}

Canopy and gap areas showed temporal changes in $R_{S}$, which were related to the temporal pattern of $T_{S}$ (Figure 7). $R_{S}$ increased with an increase in $T_{S}$ during June and July, and it peaked with the highest $T_{S}$ in August. Then, $R_{S}$ declined with decreasing $T_{S}$ during August to October. The relationship between $R_{S}$ and $T_{S}$ was fitted as an exponential equation using GLM analysis: $R_{S}=0.0207 \mathrm{e}^{0.1258 T s}$ for canopy areas, $R_{S}=0.0177 \mathrm{e}^{0.1296 T s}$ for gap areas, and $R_{S}=0.0198 \mathrm{e}^{0.1260 T s}$ for all areas. The $\mathrm{Q}_{10}$ values for canopy, gap, and all areas were calculated to be $3.52,3.65$, and 3.52, respectively.

Although the effect of $T_{s}$ on $R_{s}$ was similar in the two areas (Figure 7), the effect of $W$ on $R_{s}$ showed different patterns for canopy and gap areas. In canopy areas, $R_{S}$ increased with $W$ when $W$ ranged from $32 \%$ to $56 \%$. Meanwhile, $R_{S}$ in gap areas decreased when $\mathrm{W}$ increased during the same range.

The analysis of the full model using GLM and AIC is summarized in Table 1. The best fit for both canopy and gap areas was found with the coupling of $T_{s}$ and $W$ and the minimum AIC. All parameters related to the factors of this model were estimated (Table 2) and transformed to the equations displayed in Table 3. Figure 7 shows the relationship among $R_{s}, T_{s}$ and $W$ based on the best equations in Table 3; $R_{S}$ in canopy areas tended to increase with $T_{S}$ and $W$, and $R_{S}$ in gap areas tended to increase with $T_{S}$ and decreasing $W$.

a) Canopy

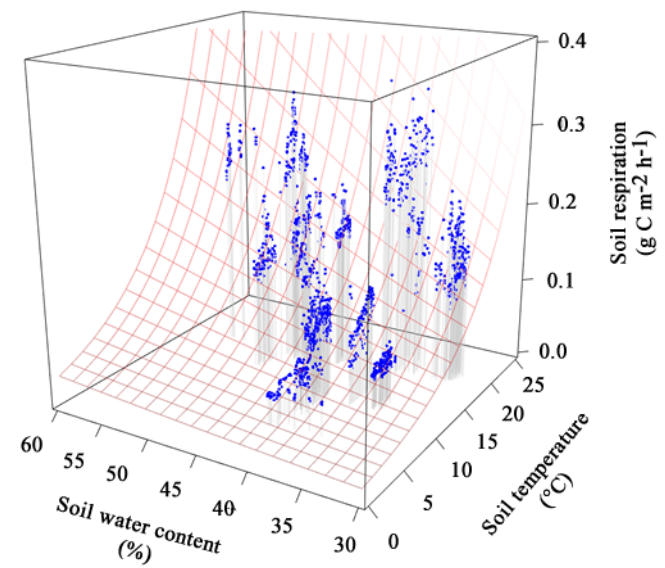

b) Gap



Figure 7. Relationships among soil respiration $\left(R_{s}\right)$, soil temperature $\left(T_{S}\right)$ and soil water content $(W)$ in canopy (a) and gap (b) areas. The regression surface shows the best fitted model in each area.

Table 1. Summary of the results of the GLMs sorted in the analysis in gap and canopy areas.

\begin{tabular}{|c|c|c|c|c|c|c|}
\hline Model & Formula & AIC & $\Delta \mathrm{AIC}$ & Deviance & $d f$ & $\begin{array}{l}\text { Dispersion } \\
\text { parameter }\end{array}$ \\
\hline \multicolumn{7}{|c|}{ Canopy } \\
\hline 1 & $R_{S} \sim a^{\prime}$ & -5167.4 & 3152.4 & 609.3 & 2025 & 0.301 \\
\hline 2 & $R_{S} \sim a^{\prime}+T_{\mathrm{S}}$ & -7236.2 & 1083.5 & 226.2 & 2024 & 0.112 \\
\hline 3 & $R_{s} \sim a^{\prime}+c \log W$ & -5270.1 & 3049.6 & 580.0 & 2024 & 0.287 \\
\hline 4 & $R_{s} \sim a^{\prime}+b T_{\mathrm{s}}+c \log W$ & -8319.7 & 0.0 & 133.4 & 2023 & 0.066 \\
\hline \multicolumn{7}{|c|}{ Gap } \\
\hline 1 & $R_{s} \sim a^{\prime}$ & -3714.9 & 1551.9 & 473.5 & 1457 & 0.325 \\
\hline 2 & $R_{S} \sim a^{\prime}+T_{S}$ & -4865.5 & 401.3 & 221.0 & 1456 & 0.125 \\
\hline 3 & $R_{s} \sim a^{\prime}+c \log W$ & -3964.1 & 1302.7 & 401.8 & 1456 & 0.276 \\
\hline 4 & $R_{S} \sim a^{\prime}+b T_{\mathrm{S}}+c \log W$ & -5266.8 & 0.0 & 168.6 & 1455 & 0.116 \\
\hline
\end{tabular}


Table 2. Summary of the estimated coefficients in model 4, which was selected as the best model based on Akaike's information criteria (AIC) in Table 1.

\begin{tabular}{ccccc}
\hline Factor & Estimate & Standard Error & $t$ Value & $p$ Value \\
\hline \multicolumn{5}{c}{ Canopy } \\
\hline (Intercept) & -10.2589 & 0.1646 & -62.33 & $<0.001$ \\
$T_{S}$ & 0.1349 & 0.0015 & 88.11 & $<0.001$ \\
$\log W$ & 1.6838 & 0.0430 & 39.20 & $<0.001$ \\
\hline \multicolumn{5}{c}{ Gap } \\
\hline (Intercept) & 4.6302 & 0.3816 & 12.14 & $<0.001$ \\
$T_{S}$ & 0.1284 & 0.0023 & 55.09 & $<0.001$ \\
$\log W$ & -2.3719 & 0.1038 & -22.86 & $<0.001$ \\
\hline
\end{tabular}

Table 3. Soil respiration $\left(R_{S}\right)$ estimated from the model using soil temperature $\left(T_{S}\right)$ and soil water content $(W) . R_{s}$ during the growing season was estimated from 27 September to 27 October 2013 and from 4 June to 26 September 2014, and $R_{S}$ during the snow season was estimated from 28 October 2013 to 3 June 2014. Total $R_{S}$ was calculated from the $R_{S}$ values of the canopy and gap areas based on their relative sizes (canopy: $74.4 \%$, gap: $25.6 \%$ ).

\begin{tabular}{clcc}
\hline \multirow{2}{*}{ Model } & & \multicolumn{2}{c}{ Estimated $\boldsymbol{R}_{\boldsymbol{s}}\left(\mathbf{g} \cdot \mathbf{C} \cdot \mathbf{m}^{-\mathbf{2}}\right)$} \\
\cline { 3 - 4 } & & Growing Season & Snow Season \\
\hline$T_{S}$ & $R_{s}=0.0198 \mathrm{e}^{0.1260 T s}$ & 437.4 & \\
All & $R_{S}=0.0207 \mathrm{e}^{0.1258 T s}$ & 507.7 & 153.7 \\
Canopy & $R_{S}=0.0177 \mathrm{e}^{0.1296 T s}$ & 451.8 & 111.8 \\
Gap & & 493.4 & 108.0 \\
Total & & & \\
\hline$T_{S} \& W$ & $R_{S}=3.5044 \times 10^{-5} \mathrm{e}^{0.1349 T s} W^{1.684}$ & 541.4 & No data \\
Canopy & $R_{S}=102.5405 \mathrm{e}^{0.1284 T s} W^{-2.372}$ & 384.6 & No data \\
Gap & & 501.3 & \\
Total & & &
\end{tabular}

\subsection{Estimation and Upscaling of $R_{S}$ to the Whole Site}

The estimated $R_{S}$ values from the $T_{S}$ dependence model and the model incorporating both $T_{S}$ and $W$ are shown in Table 3. For the growing season, estimated $R_{S}$ from the exponential relationship was lower than that from the coupled model in canopy areas, but this comparison was reversed in gap areas. During the snow season, $R_{s}$ was not affected by $W$. Thus, $R_{S}$ during this season was estimated from the specific exponential model with $T_{S}$.

On the basis of the crown closure of the study plot (canopy: $74.4 \%$ of the whole area; gap: $25.6 \%$ of the whole area), the $R_{S}$ values estimated using the model with $T_{S}$ dependence and the model with the coupling of $T_{S}$ and $W$ were 493.4 and $501.3 \mathrm{~g} \cdot \mathrm{C} \cdot \mathrm{m}^{-2}$, respectively, for the growing season. The $R_{S}$ value for the snow season estimated using the $T_{S}$ dependence model was $108.0 \mathrm{~g} \cdot \mathrm{C} \cdot \mathrm{m}^{-2}$. Therefore, the annual $R_{s}$, in which the estimated $R_{S}$ for the snow season was included, ranged between 601.4 and $609.3 \mathrm{~g} \cdot \mathrm{C} \cdot \mathrm{m}^{-2} \cdot \mathrm{year}^{-1}$. This range based on the crown closure was greater than the annual $R_{s}$ estimated using the $T_{S}$ dependence model across all areas $\left(591.1 \mathrm{~g} \cdot \mathrm{C} \cdot \mathrm{m}^{-2} \cdot\right.$ year $\left.^{-1}\right)$.

\section{Discussion}

\subsection{Effect of Soil Temperature and Soil Water Content on Soil Respiration}

Temporal change in $R_{S}$ is primarily controlled by $T_{S}$ in many temperate deciduous forests [6-8]; $R_{S}$ generally increases with an exponential increase in $T_{S}$ within the range $0-25^{\circ} \mathrm{C}$. In concurrence with 
these previous investigations, the present study showed a pattern of increasing $R_{\mathcal{S}}$ with increasing $T_{\mathcal{S}}$ (Figure 7).

In some temperate forests, $R_{s}$ is influenced not only by $T_{s}$ but also by $W$ (e.g., [3,32,34-38]). During the dry season, $W$ decreases and the diffusion of soluble substrates slows down, resulting in low $R_{S}$ [34]. This change in $R_{s}$ caused by low $W$ might support the result of the effect of low $W$ on low $R_{S}$ in canopy areas in the present study. When the soil pore space is filled with water and approaches saturation, the movement of oxygen is limited. As a result, the metabolic activity of aerobic organisms in soil decreases; thus, $R_{s}$ also decreases [38]. This probably explained why high $W$ affected low $R_{s}$ in gap areas. Without the effect of $T_{S}$, the relationship between $R_{S}$ and $W$ is generally described by a curve, which has minima at the extreme low and high values of $W$ and its maximum at the value of $W$ where the balance of water and oxygen is optimal $[9,25]$. However, in the present study, there is a possibility that $W$ values producing maximum $R_{S}$ would be quite different between canopy and gap areas. In addition, the appearance of tree coarse roots partly contributed to the increasing $R_{S}$ with $W$ in canopy areas. There is evidence that coarse root (diameter $>5 \mathrm{~mm}$ ) respiration of Pinus taeda declines at low soil water availability [39]. Therefore, because of high root biomass of large trees in canopy areas, high $W$ might induce more metabolic activity and a higher root respiration rate in canopy areas than in gap areas.

The sensitivity of the respiratory process, described by $\mathrm{Q}_{10}$, is known to be related to changes in temperature. Moreover, $\mathrm{Q}_{10}$ largely results from the confounding effect of temperature on multiple processes with covarying variables such as $W[9,40]$. The factors controlling $R_{s}$ and $Q_{10}$ across sites with varying drainage classes were investigated in mixed hardwood forests of the USA by Davidson et al. [9]. This study showed that $R_{S}$ at well-drained sites was greater than that at wetter sites, whereas $Q_{10}$ at the wetter sites was greater than that at the well-drained sites. $R_{s}$ would be less responsive to $T_{S}$ at the wetter sites than the well-drained sites because, as previously mentioned, high $W$ limits air diffusion and decreases $R_{s}$. In the present study, however, the $\mathrm{Q}_{10}$ of $R_{s}$ in canopy (3.52) and gap (3.65) areas was not different, whereas $W$ in canopy areas tended to be greater than that in gap areas (Figure 5). In addition to $W$, several studies reported that the $\mathrm{Q}_{10}$ of $R_{s}$ varied among different components in soil, for example, litter and roots [41,42]. It is possible that both $\mathrm{Q}_{10}$ and $R_{S}$ between canopy and gap areas were contributed to by the different sensitivity of soil components. For example, the gap areas had the high density of dwarf bamboo (Figure 1) but this litter is not decomposed easily because of the silica content, partly contributing to the low $R_{S}$ in gap areas. Thus, further study on the contribution of respiration from various soil components to $R_{S}$ in canopy and gap areas is needed to explain the $\mathrm{Q}_{10}$ results in the present old-growth forest.

\subsection{Estimation of Soil Respiration in the Old-Growth Forest}

The continuous measurement of temporal $R_{s}$ is necessarily required to develop models for estimation of annual $R_{s}$. Although the previous study of soil respiration in the present old-growth forest was conducted using the soda-lime method [24], this technique could not provide enough detail of diurnal and seasonal changes in $R_{s}$. The AOCC system based on closed dynamic methods allows continuous measurement of $R_{s}$, creating enough data to understand the relationship between diurnal and seasonal $R_{S}$ and environmental factors. This method has been used in some forests [3,11-14] but is rarely used in old-growth forests. Using this system in the present study site sometimes resulted in some problems, in addition to no electricity, for example, the chambers could not fully close due to heavy rain. However, the AOCC system provided sufficient and detailed $R_{S}$ measurements in the present study.

For evaluation of annual $R_{S}$ using equations, seasonal $R_{S}$ has often been estimated using only $T_{S}$ dependence as an exponential relationship in forests where $W$ is not limiting (e.g., [6-8,43-45]). However, in forests where there is a drying period, $R_{S}$ has been estimated by the coupling of $T_{S}$ and $W$, although an empirical model using these variables has been unclear [3,31,35-39]. In the present study, the GLM analysis identified the model with the coupling of $T_{s}$ and $W$ as the best model (Table 1). This 
model also had more accuracy than the model with only $T_{s}$ because the model with the coupling of $T_{S}$ and $W$ included responses of $R_{S}$ to $W$, which differed between gap and canopy areas (Figure 7). Therefore, the empirical model with the coupling of $T_{S}$ and $W$ was suitable for the estimation of $R_{S}$ for the growing season at the present study site.

At the stand level, the high spatial variability in $R_{s}$ resulted from large variations in, for example, $W$ [46], soil physical properties [24,47-49], fine root biomass [23,24,36,37,50,51], and stand structure [25,46]. A few studies have addressed this spatial variation for upscaling $R_{s}$ from different measurement points to the site scale $[25,46]$. In the present old-growth forest, there was a clear gap and canopy structure, and the high $R_{S}$ in the canopy areas could represent the high root respiration because of high root biomass [24]. Additionally, different responses of $R_{s}$ to $W$ between canopy and gap areas were found in the present study. Thus, the estimation of $R_{S}$ should be conducted separately for canopy and gap areas. The estimation of annual $R_{S}$ with the crown closure could reflect a respective range of $R_{s}$ values across all gaps to all canopies as 481.6 to $653.2 \mathrm{~g} \cdot \mathrm{C} \cdot \mathrm{m}^{-2} \cdot$ year $^{-1}$. Therefore, the combination of the spatial patterns of $R_{s}$, particularly canopy and gap areas, and the crown closure could be used for upscaling $R_{S}$ from chamber measurements to the stand level in old-growth forests.

\section{Conclusions}

In the present old-growth forest, the structural complexity created by canopy and gap spaces induced different responses of $R_{S}$ to $T_{S}$ and W. $R_{S}$ increased with increasing $T_{S}$ in both canopy and gap areas, and $Q_{10}$ values in these areas were not different. In terms of the effect of $W$ on $R_{s}$, this relationship differed between canopy and gap areas; $R_{s}$ increased with $W$ in canopy areas, but $R_{S}$ tended to decrease with $W$ in gap areas. Consequently, to understand the influence of $T_{S}$ and $W$ on $R_{S}$ estimation, the GLM analysis identified that an empirical model that couples these factors $\left(T_{S}\right.$ and $\left.W\right)$ was better than a simple exponential model with only $T_{S}$. Because of these results, it was necessary to estimate $R_{S}$ in canopy and gap areas separately. Additionally, combining the unique spatial patterns of $R_{S}$ and the area of the crown closure could allow for upscaling of $R_{s}$ from field measurements to the whole site in old-growth forests.

Acknowledgments: We thank members of the Takayama Forest Research Station, the Institute for Basin Ecosystem Studies, Gifu University, for providing their facilities during the field survey. We also thank members of the laboratory of the Institute for Basin Ecosystem Studies, Gifu University, for their assistance with field measurements.

Author Contributions: V.S. and T.O. conceived and designed the experiments; V.S., S.Y., Y.I. and T.O. performed the experiments; V.S. and M.A. analyzed the data; M.H. contributed materials tools; V.S. wrote the paper.

Conflicts of Interest: The authors declare no conflict of interest.

\section{References}

1. Liu, Q.; Edwards, N.T.; Post, W.M.; Gu, L.; Ledford, J.; Lenhart, S. Temperature-independent diel variation in soil respiration observed from a temperate deciduous forest. Glob. Chang. Biol. 2006, 12, 2136-2145. [CrossRef]

2. Hashimoto, T.; Miura, S.; Ishizuka, S. Temperature controls temporal variation in soil $\mathrm{CO}_{2}$ efflux in a secondary beech forest in Appi Highlands, Japan. J. For. Res. 2009, 14, 44-50. [CrossRef]

3. Joo, S.J.; Park, S.U.; Park, M.S.; Lee, C.S. Estimation of soil respiration using automated chamber systems in an oak (Quercus mongolica) forest at the Nam-San site in Seoul, Korea. Sci. Total Environ. 2012, 416, 400-409. [CrossRef] [PubMed]

4. Kishimoto-Mo, A.W.; Yonemura, S.; Uchida, M.; Kondo, M.; Murayama, S.; Koizumi, H. Contribution of soil moisture to seasonal and annual variations of soil $\mathrm{CO}_{2}$ efflux in a humid cool-temperate oak-birch forest in central Japan. Ecol. Res. 2015, 30, 311-325. [CrossRef]

5. Xu, M.; Qi, Y. Soil-surface $\mathrm{CO}_{2}$ efflux and its spatial and temporal variations in a young ponderosa pine plantation in Northern California. Glob. Chang. Biol. 2001, 7, 667-677. [CrossRef] 
6. Mo, W.; Lee, M.; Uchida, M.; Inatomi, M.; Saigusa, N.; Mariko, S.; Koizumi, H. Seasonal and annual variations in soil respiration in a cool-temperate deciduous broad-leaved forest in Japan. Agric. For. Meteorol. 2005, 134, 81-94. [CrossRef]

7. Ohtsuka, T.; Shizu, Y.; Nishiwaki, A.; Yashiro, Y.; Koizumi, H. Carbon cycling and net ecosystem production at an early stage of secondary succession in an abandoned coppice forest. J. Plant Res. 2010, 123, 393-401. [CrossRef] [PubMed]

8. Inoue, T.; Nagai, S.; Inoue, S.; Ozaki, M.; Sakai, S.; Muraoka, H.; Koizumi, H. Seasonal variability of soil respiration in multiple ecosystems under the same physical-geographical environmental conditions in central Japan. For. Sci. Technol. 2012, 8, 52-60. [CrossRef]

9. Davidson, E.A.; Belk, E.; Boone, R. Soil water content and temperature as independent of confounded factors controlling soil respiration in a temperate mixed hardwood forest. Glob. Chang. Biol. 1998, 4, 217-227. [CrossRef]

10. Wang, Y.; Hao, Y.; Cui, X.Y.; Zhao, H.; Xu, C.; Zhou, X.; Xu, Z. Responses of soil respiration and its components to drought stress. J. Soil Sediments 2013, 14, 99-109. [CrossRef]

11. Irvine, J.; Law, B.E. Contrasting soil respiration in young and old-growth ponderosa pine forests. Glob. Chang. Biol. 2002, 8, 1183-1194. [CrossRef]

12. Edwards, N.T.; Riggs, J.S. Automated monitoring of soil respiration: A moving chamber design. Soil Sci. Soc. Am. J. 2003, 67, 1266-1271. [CrossRef]

13. Liang, N.; Inoue, G.; Fujinuma, Y. A multichannel automated chamber system for continuous measurement of forest soil $\mathrm{CO}_{2}$ efflux. Tree Physiol. 2003, 23, 825-832. [CrossRef] [PubMed]

14. Suh, S.U.; Chun, Y.M.; Chae, N.; Kim, J.; Lim, J.H.; Yokozawa, M.; Lee, M.S.; Lee, J.S. A chamber system with automatic opening and closing for continuously measuring soil respiration based on an open-flow dynamic method. Ecol. Res. 2006, 21, 405-414. [CrossRef]

15. Nakashizuka, T.; Numata, M. Regeneration process of climax beech forests: I. Structure of a beech forest with the undergrowth of Sasa. Jpn. J. Ecol. 1982, 32, 57-67.

16. Tanouchi, H.; Yamamoto, S. Structure and regeneration of canopy species in an old-growth evergreen broad-leaved forest in Aya district, Southwestern Japan. Vegetation 1995, 117, 51-60. [CrossRef]

17. Manabe, T.; Nishimura, N.; Miura, M.; Yamamoto, S. Population structure and spatial patterns for trees in a temperate old-growth evergreen broad-leaved forest in Japan. Plant Ecol. 2000, 151, 181-197. [CrossRef]

18. Miura, M.; Manabe, T.; Nishimura, N.; Yamamoto, S. Forest canopy and community dynamics in a temperate old-growth evergreen broad-leaved forest, south-western Japan: A 7-year study of a 4-ha plot. J. Ecol. 2001, 89, 841-849. [CrossRef]

19. Matsushita, M.; Hoshino, D.; Yamamoto, S.; Nishimura, N. Twenty-three years and dynamics in an old-growth Chamaecyparis forest in central Japan. J. For. Res. 2014, 19, 134-142. [CrossRef]

20. Suchewaboripont, V.; Iimura, Y.; Yoshitake, S.; Kato, S.; Komiyama, A.; Ohtsuka, T. Change in biomass of an old-growth beech-oak forest of Mt. Hakusan over a 17-year period. Jpn. J. For. Environ. 2015, 57, $33-42$.

21. Hardiman, B.S.; Bohrer, G.; Gough, C.M.; Vogel, C.S.; Curtis, P.S. The role of canopy structural complexity in wood net primary production of a maturing northern deciduous forest. Ecology 2011, 92, 1818-1827. [CrossRef] [PubMed]

22. Hardiman, B.S.; Gough, C.M.; Halperin, A.; Hofmeister, K.L.; Nave, L.E.; Bohrer, G.; Curtis, P.S. Maintaining high rates of carbon storage in old forests: A mechanism lining canopy structure to forest function. For. Ecol. Manag. 2013, 298, 111-119. [CrossRef]

23. Hojjati, S.M.; Lamersdorf, N.P. Effect of canopy composition on soil $\mathrm{CO}_{2}$ emission in a mixed spruce-beech forest at Solling, Central Germany. J. For. Res. 2010, 21, 461-464. [CrossRef]

24. Suchewaboripont, V.; Ando, M.; Iimura, Y.; Yoshitake, S.; Ohtsuka, T. The effect of canopy structure on soil respiration in an old-growth beech-oak forest in central Japan. Ecol. Res. 2015, 30, 867-877. [CrossRef]

25. Tang, J.; Baldocchi, D.D. Spatial-temporal variation in soil respiration in an oak-grass savanna ecosystem in California and its partitioning into autotrophic and heterotrophic components. Biogeochemistry 2005, 73, 183-207. [CrossRef]

26. Geological Survey of Japan, AIST (Ed.) Catalog of Eruptive Events during the Last 10,000 Years in Japan, Version 2.2. Available online: https://gbank.gsj.jp/volcano/eruption/index.html (accessed on 29 December 2016). 
27. Kato, S.; Komiyama, A. Distribution patterns of understory trees and diffuse light under the canopy of a beech forest. Jpn. J. Ecol. 1999, 49, 1-10.

28. Runkle, J.R. Gap regeneration in some old-growth forests of the eastern United States. Ecology 1981, 62, 1041-1051. [CrossRef]

29. Hirota, M.; Zhang, P.; Gu, S.; Shen, H.; Kuriyama, T.; Li, Y.; Tang, Y. Small-scale variation in ecosystem $\mathrm{CO}_{2}$ fluxes in an alpine meadow depends on plant biomass and species richness. J. Plant Res. 2010, 123, 531-541. [CrossRef] [PubMed]

30. Abbas, F.; Fares, A.; Fares, S. Field calibrations of soil moisture sensors in a forested watershed. Sensors 2011, 11, 6354-6369. [CrossRef] [PubMed]

31. Yang, Y.S.; Chen, G.S.; Guo, J.F.; Xie, J.S.; Wang, X.G. Soil respiration and carbon balance in a subtropical native forest and two managed plantations. Plant Ecol. 2007, 193, 71-84. [CrossRef]

32. R Development Core Team. R: A Language and Environment for Statistical Computing; R Foundation for Statistical Computing: Vienna, Austria, 2014.

33. Bates, D.; Maechler, M.; Bolker, B.; Walker, S. lme4: Linear Mixed-Effects Models Using Eigen and S4. R Package Version 1.1-7. 2014. Available online: http:/ /CRAN.R-project.org/package=lme4 (accessed on 22 April 2016).

34. Epron, D.; Farque, L.; Lucot, É.; Badot, P.M. Soil $\mathrm{CO}_{2}$ efflux in a beech forest: Dependence on soil temperature and soil water content. Ann. For. Sci. 1999, 56, 221-226. [CrossRef]

35. Qi, Y.; $\mathrm{Xu}, \mathrm{M}$. Separating the effects of moisture and temperature on soil $\mathrm{CO}_{2}$ efflux in a coniferous forest in the Sierra Nevada mountains. Plant Soil 2001, 237, 15-23. [CrossRef]

36. Søe, A.R.B.; Buchmann, N. Spatial and temporal variations in soil respiration in relation to stand structure and soil parameters in an unmanaged beech forest. Tree Physiol. 2005, 25, 1427-1436. [CrossRef] [PubMed]

37. Knohl, A.; Søe, A.R.B.; Kutsch, W.L.; Göckede, M.; Buchmann, N. Representative estimates of soil and ecosystem respiration in an old beech forest. Plant Soil 2008, 302, 189-202. [CrossRef]

38. Tomotsune, M.; Masuda, R.; Yoshitake, S.; Anzai, T.; Koizumi, H. Seasonal and inter-annual variations in contribution ratio of heterotrophic respiration to soil respiration in a cool-temperate deciduous forest. J. Geogr. 2013, 122, 745-754. [CrossRef]

39. Maier, C.A.; Kress, L. Soil $\mathrm{CO}_{2}$ evolution and root respiration in 11 year-old loblolly pine (Pinus taeda) plantations as affected by moisture and nutrient. Can. J. For. Res. 2000, 30, 347-359. [CrossRef]

40. Dörr, H.; Münnich, K.O. Annual variation in soil respiration in selected areas of the temperate zone. Tellus 1987, 39, 114-121. [CrossRef]

41. Boone, R.D.; Nadelhoffer, K.J.; Canary, J.D.; Kaye, J.P. Roots exert a strong influence on the temperature sensitivity of soil respiration. Nature 1998, 396, 570-572. [CrossRef]

42. Liski, J.; Ilvesniemi, H.; Mäkelä, A.; Westman, C.J. CO $\mathrm{CO}_{2}$ emissions from soil in response to climatic warming are overestimated: The decomposition of old soil organic matter is tolerant of temperature. Ambio 1999, 28, 171-174.

43. Liang, N.; Hirano, T.; Zheng, Z.-M.; Tang, J.; Fujinuma, Y. Soil $\mathrm{CO}_{2}$ efflux of a larch forest in Northern Japan. Biogeosciences 2010, 7, 3447-3457. [CrossRef]

44. Vesterdal, L.; Elberling, B.; Christiansen, J.R.; Callesen, I.; Schmidt, I.K. Soil respiration and rates of soil carbon turnover differ among six common European tree species. For. Ecol. Manag. 2012, 264, 185-196. [CrossRef]

45. Luan, J.; Liu, S.; Wang, J.; Zhu, X. Factors affecting spatial variation of annual apparent $\mathrm{Q}_{10}$ of soil respiration in two warm temperate forests. PLoS ONE 2013, 8, e64167. [CrossRef] [PubMed]

46. Jia, S.; Akiyama, T.; Mo, W.; Inatomi, M.; Koizumi, H. Temporal and spatial variability of soil respiration in a cool-temperate broad-leaved forest 1 . Measurement of spatial variance and factor analysis. Jpn. J. Ecol. 2003, 53, 13-22.

47. Scott-Denton, L.E.; Sparks, K.L.; Monson, R.K. Spatial and temporal controls of soil respiration rate in a high-elevation, subalpine forest. Soil Biol. Biochem. 2003, 35, 525-534. [CrossRef]

48. Saiz, G.; Green, C.; Butterbach-Bahl, K.; Kiese, R.; Avitabile, V.; Farrell, E.P. Seasonal and spatial variability of soil respiration in four Sitka spruce stands. Plant Soil 2006, 287, 161-176. [CrossRef]

49. Ngao, J.; Epron, D.; Delpierre, N.; Bréda, N.; Granier, A.; Longdoz, B. Spatial variability of soil $\mathrm{CO}_{2}$ efflux linked to soil parameters and ecosystem characteristics in a temperate beech forest. Agric. For. Meteorol. 2012, 154-155, 136-146. [CrossRef] 
50. Stoyan, H.; De-Polli, H.; Böhm, S.; Robertson, G.P.; Paul, E.A. Spatial heterogeneity of soil respiration and related properties at the plant scale. Plant Soil 2000, 222, 203-214. [CrossRef]

51. Adachi, M.; Bekku, Y.S.; Rashidah, W.; Okuda, T.; Koizumi, H. Differences in soil respiration between different tropical ecosystems. Appl. Soil Ecol. 2006, 34, 258-265. [CrossRef]

(c) 2017 by the authors; licensee MDPI, Basel, Switzerland. This article is an open access article distributed under the terms and conditions of the Creative Commons Attribution (CC BY) license (http:/ / creativecommons.org/licenses/by/4.0/). 